\title{
Management of acute bronchiolitis: can evidence based guidelines alter clinical practice?
}

\author{
J Barben, ${ }^{1}$ C E Kuehni, ${ }^{2}$ D Trachsel, ${ }^{3}$ J Hammer, ${ }^{3}$ on behalf of the Swiss Paediatric \\ Respiratory Research Group
}

${ }^{1}$ Children's Hospital, St Gallen, Switzerland; ${ }^{2}$ Institute of Social and Preventive Medicine (ISPM), University of Bern, Switzerland; ${ }^{3}$ University Children's Hospital Basel, Switzerland

Correspondence to: Dr J Barben, Paediatric Pulmonology, Children's Hospital, CH-9006 St Gallen, Switzerland; juerg.barben@ kispisg.ch

$\mathrm{J}$ Barben and C E Kuehni contributed equally to this paper.

Received 10 January 2008 Accepted 22 July 2008 Published Online First 22 August 2008

\section{ABSTRACT}

Background: Acute bronchiolitis is the most common lower respiratory tract infection in infants and there is no evidence that drug treatment alters its natural course. Despite this, most Swiss paediatricians reported in 2001 prescribing bronchodilators and inhaled corticosteroids (ICS). This situation led to the creation of national guidelines followed by a tailored implementation programme. The aim of this study was to examine if treatment practices changed after the implementation of the new guidelines.

Methods: A questionnaire on treatment of bronchiolitis was sent to all Swiss paediatricians before (2001) and after (2006) creation and implementation of national guidelines (2003-2005). Guidelines were created in collaboration with all paediatric pulmonologists and implemented carefully using a multifaceted approach.

Results: Questionnaires were returned by 541 paediatricians (58\%) in 2001 and by 639 (54\%) in 2006. While both surveys showed a wide variation in the treatment of bronchiolitis between physicians, reported drug prescription decreased significantly between the two surveys. For outpatients, general use (for all patients) of bronchodilators dropped from $60 \%$ to $23 \%$, and general use of ICS from $34 \%$ to $6 \%$. For inpatients, general use of bronchodilators and ICS dropped from $55 \%$ to $18 \%$ and from $26 \%$ to $6 \%$, respectively (all $p<0.001$ ). The decrease was evident in all regions, among hospital and primary care physicians, and among general paediatricians and paediatric pulmonologists.

Conclusions: National guidelines together with a tailored implementation programme can have a major impact on medical management practices in a country.

Healthcare professionals are increasingly urged to base clinical practice on scientific evidence but implementation of research findings into routine daily practice is a major challenge. ${ }^{1-3}$ To date, most dissemination and implementation strategies have resulted in small to moderate improvements. ${ }^{4}$ Some strategies to change practices of health care professionals have been successful while others have not. ${ }^{5}$ Evidence based guidelines, published by many medical organisations, are often not very effective on their own. ${ }^{78}$ Instead, it has been suggested to design tailored interventions in order to implement these guidelines and change behaviour in daily practice. ${ }^{9}$

Acute bronchiolitis is the most common lower respiratory tract infection in infancy, with a typical clinical presentation of respiratory distress, crackles and wheezing. ${ }^{10}$ Its treatment is largely supportive, including oxygen therapy, fluid management, avoidance of unnecessary handling and respiratory support. ${ }^{10}$ Systematic reviews suggest that available therapies will not shorten its natural course or provide clinically relevant improvements in symptoms. This is true for $\beta_{2}$ agonists, epinephrine, anticholinergics and both inhaled and oral corticosteroids. ${ }^{11-16}$ Nevertheless, all of these agents are used widely for the treatment of bronchiolitis. ${ }^{17}{ }^{18}$ In Switzerland, a survey in 2001 showed that almost all paediatricians prescribed bronchodilators and inhaled corticosteroids (ICS) for outpatients and inpatients suffering from bronchiolitis. ${ }^{19}$ To change this situation, the Swiss Association of Paediatric Pulmonology (SAPP/SGPP) developed national guidelines for the management of acute bronchiolitis and viral induced wheeze in 2003 and $2004,{ }^{20}$ and took a range of measures to implement these. Both guidelines discouraged the use of any pharmaceutical agents or physiotherapy in previously healthy infants with bronchiolitis.

The aim of our study was to determine the effect of the new guidelines and their implementation by comparing self-reported management practices of all Swiss paediatricians before and after introduction of the new guidelines.

\section{METHODS}

\section{Study design and subjects}

We performed two cross sectional questionnaire surveys of all Swiss paediatricians in 2001 and 2006. The names and addresses of all paediatricians were provided by the Swiss Society of Paediatrics. We received a complete list of all qualified paediatricians in Switzerland, irrespective of their place of work (primary paediatric practice, hospital). Paediatric trainees were not included in the list, but a small number of retired colleagues may have been. A subgroup of these paediatricians, organised in the SAPP/SGPP, had formal subspecialty training or a special interest in paediatric pulmonology. Depending on the region, questionnaires were sent in French or German. To improve response rate and minimise selection bias, the questionnaires were returned anonymously in a prepaid envelope, and did not include information on sex, age or position of the physicians. For the same reason it was impossible to send reminders to non-responders.

\section{Questionnaires}

For both surveys we used an identical standardised questionnaire on management practices of bronchiolitis in infants. ${ }^{19}{ }^{21}$ All paediatricians were asked to complete at least the first question (Do you 
treat children with bronchiolitis-yes or no?). For those currently treating patients, the questionnaire contained two further sections relating separately to the management of outpatients and inpatients. We asked if they used the following drugs: bronchodilators (salbutamol, ipratropium bromide, adrenaline), corticosteroids (systemic, inhaled), cromoglycates, antibiotics, nasal drops, theophylline, ribavirin and physiotherapy. Answer categories for all questions were: "always", "sometimes", "only for high risk children" (children with underlying diseases, including bronchopulmonary dysplasia, cystic fibrosis, heart diseases, immunodeficiency and neurological disorders) and "never". In addition, we asked if they performed virological examinations of nose or throat swabs.

\section{Development and implementation of national guidelines}

In 2003 and 2004, SAPP/SGPP developed and published two guidelines. The first one focused on the distinct disease phenotype "bronchiolitis in infants".22 The second one, published a year later, was more comprehensive and contained guidelines on the treatment of different phenotypes of obstructive airway disorders in infants and children, including bronchiolitis but also viral wheeze in older children and atopic asthma. ${ }^{23}$ Both guidelines were based on available evidence, mainly systematic reviews and meta-analyses, and were developed in several steps involving a large group of interested paediatric pulmonologists in Switzerland. Efforts were made to involve both hospital physicians and those working in primary practice, and we made sure that representatives from all regions and languages were included in the guideline development group. Both guidelines recommend abandoning all pharmacological and non-pharmacological therapies of bronchiolitis for which scientific evidence is clearly missing. The only treatment recommended by the guidelines was the use of nasal drops to optimise nasal breathing, although it was admitted that the evidence to support this recommendation was insufficient.

A multifaceted implementation strategy was developed. The official guidelines and several commentaries were published between 2003 and 2005 in German and French in all major official journals for paediatricians and general practitioners in Switzerland, including official publications of the Swiss Medical Association and the Swiss Society of Paediatrics (SSP), but also a

Table 1 Characteristics of participating physicians in 2001 and 2006

\begin{tabular}{lccc}
\hline & $\begin{array}{l}\text { 2001 survey } \\
(\mathbf{n}(\%))\end{array}$ & $\begin{array}{l}\text { 2006 survey } \\
(\mathbf{n}(\%))\end{array}$ & p Value \\
\hline Language & & & \\
$\quad$ German & $279(66.1)$ & $331(66.5)$ & 0.90 \\
$\quad$ French & $143(33.9)$ & $167(33.5)$ & \\
Physician specialty & & & \\
$\quad$ Paediatric pulmonologist (qualified) & $16(3.8)$ & $18(3.6)$ & 0.34 \\
$\quad$ Paediatric pulmonologist (interest) & $21(5.0)$ & $13(2.6)$ & \\
$\quad$ General paediatrician and other & $385(91.2)$ & $467(93.8)$ & \\
$\quad$ subspecialist & & & \\
Work place & & & \\
$\quad$ Hospital & $102(24.2)$ & $153(30.7)$ & 0.05 \\
$\quad$ Private practice & $301(71.3)$ & $331(66.5)$ & \\
$\quad$ Unclear & $19(4.5)$ & $14(2.8)$ & \\
No of bronchiolitis patients treated/year & & & \\
$\quad<10$ & $133(31.5)$ & $125(25.1)$ & 0.15 \\
10-50 & $241(57.1)$ & $306(61.5)$ & \\
$>50$ & $37(8.8)$ & $55(11.0)$ & \\
$\quad$ Missing & $11(2.6)$ & $12(2.4)$ & \\
Total & $422(100.0)$ & $498(100.0)$ & \\
\hline
\end{tabular}

number of other scientific and popular medical journals. ${ }^{2022-26}$ Furthermore, the guidelines were presented by a number of dedicated speakers of the SAPP/SGPP at the main national meetings and annual conferences (SAPP/SGPP, SSP, Swiss Society of Pulmonology and Paediatric Forum, the organisation for paediatricians working in private practice) and at local teaching rounds in university hospitals and regional hospitals (advanced training and continuing education for practitioners) targeting registrars and paediatricians working in primary, secondary and tertiary care all over Switzerland. In addition, a parent information leaflet was created in German and French (http://www.sgpp-schweiz.ch/go2/de/publikationen) and sent to all Swiss paediatricians for distribution to parents. The leaflet explained the disease in a simple language, highlighted that drug treatment usually did not help and counselled parents how to treat their babies. Guidelines and information leaflets can be downloaded on the official website of the SAPP/SGPP (www. sgpp-schweiz.ch) and the SSP (www.swiss-paediatrics.org).

\section{Statistical analysis}

The data were analysed using Stata, V.9.2 (Stata Corporation, Austin, Texas). We tabulated the frequency of reported use for the different drugs, comparing the two surveys in 2001 and 2006. $\chi^{2}$ tests, $\chi^{2}$ tests for trend and Fisher's exact tests were performed as appropriate to assess statistical significance in comparison of proportions. Binary logistic regression and ordered logistic regression models were used to compare treatment frequency between the two surveys, adjusting for the covariates language, physician subspecialty, place of work (hospital, private practice) and number of patients treated annually. Results were expressed as odds ratios (OR) with 95\% confidence intervals; likelihood ratio tests were performed to compare different models. Effect modification was tested by comparing models with and without inclusion of interaction terms.

\section{RESULTS}

Response rates and characteristics of participating physicians In 2001, 937 questionnaires were posted and 541 (58\%) returned. In 2006, the response rate was 639/1188 (54\%). Among these questionnaires, $119(22 \%)$ in 2001 and $150(23 \%)$ in 2006, respectively, came from physicians who did not treat children with acute bronchiolitis, leaving 422 (2001) and 498 (2006) for analysis.

In both years, about one-third of respondents were French and two-thirds were German speaking (table 1). Twenty-four per cent (2001) and 31\% (2006) worked in hospitals, the others in private practice. About $9 \%$ in 2001 (6\% in 2006) were qualified paediatric respiratory physicians or had a special interest in paediatric respiratory medicine.

The practice used to identify the causative viral agent remained stable over the observed period. In 2001, $44(10 \%)$ physicians performed nose or throat swabs in all outpatients to identify respiratory viruses, 163 (39\%) performed them sometimes, 90 (21\%) only for high risk children and 197 (25\%) never (with 18 (4\%) missing answers). In 2006, the respective numbers were 28 (6\%) always, 202 (41\%) sometimes, 109 (22\%) only for high risk children and 135 (37\%) never (with 24 (5\%) missing).

\section{Reported drug prescription for acute bronchiolitis in 2001 and 2006}

A wide variation in reported treatment of bronchiolitis was found in both surveys, for inpatients and outpatients. For 
Table 2 Reported management of outpatients with acute bronchiolitis in 2001 and 2006

\begin{tabular}{|c|c|c|c|c|c|c|c|c|c|c|c|}
\hline & \multicolumn{5}{|c|}{2001 survey $(n=422)$} & \multicolumn{5}{|c|}{2006 survey $(n=498)$} & \multirow[b]{2}{*}{ p Value } \\
\hline & Always & Sometimes & High risk & Never & Missing & Always & Sometimes & High risk & Never & Missing & \\
\hline Salbutamol & 254 & 149 & 1 & 2 & 16 & 117 & 314 & 8 & 32 & 27 & $<0.001$ \\
\hline \multirow[t]{2}{*}{ Ipratropium bromide } & 9 & 108 & 4 & 162 & 139 & 2 & 98 & 2 & 273 & 123 & 0.004 \\
\hline & 2.1 & 25.6 & 1.0 & 38.4 & 32.9 & 0.4 & 19.7 & 0.4 & 54.8 & 24.7 & \\
\hline Cromoglycates & 10 & 62 & 1 & 289 & 60 & 10 & 37 & 1 & 405 & 45 & 0.002 \\
\hline Steroids (any) & 35.1 & 49.1 & 2.4 & 7.4 & 6.2 & 8.0 & 51.6 & 5.2 & 27.9 & 7.2 & \\
\hline \multirow[t]{2}{*}{ Inhaled } & 143 & 197 & 9 & 35 & 38 & 32 & 205 & 24 & 171 & 66 & $<0.001$ \\
\hline & 33.9 & 46.7 & 2.1 & 8.3 & 9.0 & 6.4 & 31.2 & 4.8 & 34.3 & 13.3 & \\
\hline \multirow[t]{2}{*}{ Systemic } & 14 & 142 & 13 & 137 & 116 & 12 & 163 & 19 & 238 & 66 & 0.769 \\
\hline & 3.3 & 33.7 & 3.1 & 32.5 & 27.5 & 2.4 & 32.7 & 3.8 & 47.8 & 13.3 & \\
\hline Antibiotics & 6 & 148 & 75 & 157 & 36 & 3 & 85 & 59 & 302 & 49 & $<0.001$ \\
\hline Xylometazoline & 13.7 & 63.5 & 0.7 & 9.0 & 13.0 & 27.1 & 58.4 & 0.4 & 6.2 & 7.8 & \\
\hline \multirow[t]{2}{*}{$\mathrm{NaCl} 0.9 \%$} & 176 & 169 & 0 & 12 & 65 & 278 & 159 & 1 & 10 & 50 & 0.001 \\
\hline & 41.7 & 40.1 & 0.0 & 2.8 & 15.4 & 55.8 & 31.9 & 0.2 & 2.0 & 10.0 & \\
\hline \multirow[t]{2}{*}{ Physiotherapy } & - & - & - & - & - & 20 & 184 & 43 & 185 & 66 & NA \\
\hline & - & - & - & - & - & 4.0 & 36.9 & 8.6 & 37.1 & 13.2 & \\
\hline
\end{tabular}

Data are presented as $\mathrm{n}$ (first line) and row per cent (second line) for each treatment. Data from hospital based and primary care physicians are included. $\mathrm{p}$ Values are derived from Fisher's exact test.

outpatients (table 2), salbutamol, ICS and nasal drops were the most commonly prescribed drugs. The frequency of salbutamol and ICS use decreased steeply between the two surveys: general use (for all children) of salbutamol from $60 \%$ in 2001 to $23 \%$ in $2006(p<0.001)$, and general use of ICS from $34 \%$ to $6 \%$ $(p<0.001)$. Use of antibiotics ("sometimes") in outpatients decreased from $35 \%$ to $17 \%(p<0.001)$. Nasal drops was the only medication that was more frequently prescribed between the two surveys, with $45 \%$ of physicians prescribing them for all children in 2001 and $60 \%$ in 2006 ( $p<0.001)$.

Changes in reported drug treatment of inpatients were similar (table 3). In 2001, 55\% of paediatricians always used salbutamol and $26 \%$ ICS for inpatients. In 2006, these proportions decreased to $18 \%$ and $6 \%$, respectively $(p<0.001)$. The number of physicians always prescribing physiotherapy decreased from $42 \%$ in 2001 to $14 \%$ in $2006(p<0.001)$.

Table 3 Reported management of inpatients with acute bronchiolitis in 2001 and 2006

\begin{tabular}{|c|c|c|c|c|c|c|c|c|c|c|c|}
\hline & \multicolumn{5}{|c|}{2001 survey $(n=102)$} & \multicolumn{5}{|c|}{2006 survey $(n=153)$} & \multirow[b]{2}{*}{ p Value } \\
\hline & Always & Sometimes & High risk & Never & Missing & Always & Sometimes & High risk & Never & Missing & \\
\hline Salbutamol & 56 & 43 & 1 & 2 & 0 & 27 & 110 & 5 & 11 & 0 & $<0.001$ \\
\hline \multirow[t]{2}{*}{ Ipratropium bromide } & 5 & 49 & 2 & 37 & 9 & 4 & 45 & 3 & 98 & 3 & 0.006 \\
\hline & 4.9 & 48.0 & 2.0 & 36.3 & 8.8 & 2.6 & 29.4 & 2.0 & 64.1 & 2.0 & \\
\hline Adrenaline & 1 & 35 & 3 & 51 & 12 & 1 & 33 & 4 & 107 & 8 & 0.100 \\
\hline Steroids (any) & 27.5 & 52.0 & 5.9 & 14.7 & 0.0 & 7.2 & 45.1 & 7.8 & 39.9 & 0.0 & \\
\hline \multirow[t]{2}{*}{ Inhaled } & 27 & 51 & 4 & 20 & 0 & 10 & 60 & 9 & 74 & 0 & $<0.001$ \\
\hline & 26.5 & 50.0 & 3.9 & 19.6 & 0.0 & 6.5 & 39.2 & 5.9 & 48.4 & 0.0 & \\
\hline \multirow[t]{2}{*}{ Systemic } & 5 & 51 & 11 & 35 & 0 & 3 & 58 & 11 & 81 & 0 & 0.020 \\
\hline & 4.9 & 50.0 & 10.8 & 34.3 & 0.0 & 2.0 & 37.9 & 7.2 & 52.9 & 0.0 & \\
\hline Theophylline & 1 & 13 & 4 & 81 & 3 & 0 & 8 & 6 & 138 & 1 & 0.074 \\
\hline Physiotherapy & 42.2 & 47.1 & 3.9 & 5.9 & 1.0 & 14.4 & 58.8 & 6.5 & 19.6 & 0.7 & \\
\hline
\end{tabular}

Data are presented as $\mathrm{n}$ (first line) and row per cent (second line) for each treatment. Only questionnaires from hospital based physicians are included and therefore numbers are lower than in table 2.

$\mathrm{p}$ Values are derived from Fisher's exact test. 
Table 4 Determinants of reported frequency of use of salbutamol, inhaled steroids and antibiotics in outpatients with acute bronchiolitis

\begin{tabular}{|c|c|c|c|c|c|c|c|c|}
\hline & \multicolumn{4}{|c|}{2001 survey ( $n=422$ ) } & \multicolumn{4}{|c|}{2006 survey $(n=498$ ) } \\
\hline & \multicolumn{2}{|l|}{ Unadjusted } & \multicolumn{2}{|l|}{ Adjusted* } & \multicolumn{2}{|l|}{ Unadjusted } & \multicolumn{2}{|l|}{ Adjusted* } \\
\hline & OR $(95 \% \mathrm{Cl})$ & p Value & OR $(95 \% \mathrm{Cl})$ & p Value & OR $(95 \% \mathrm{Cl})$ & p Value & OR $(95 \% \mathrm{Cl})$ & p Value \\
\hline French (vs German) & $2.00(1.28$ to 3.10$)$ & 0.002 & 2.55 (1.54 to 4.22 ) & $<0.001$ & 0.87 (0.59 to 1.30$)$ & 0.508 & 0.90 (0.60 to 1.36$)$ & 0.626 \\
\hline Paediatric pulmonologists & $0.37(0.18$ to 0.76$)$ & 0.007 & 0.69 (0.32 to 1.52$)$ & 0.360 & 0.31 (0.13 to 0.75 ) & 0.009 & 0.43 (0.18 to 1.03 ) & 0.060 \\
\hline Hospital based vs practice & $0.46(0.29$ to 0.74$)$ & 0.001 & $0.41(0.25$ to 0.70$)$ & 0.001 & $0.44(0.28$ to 0.69$)$ & $<0.001$ & 0.54 (0.34 to 0.87$)$ & 0.010 \\
\hline French (vs German) & 2.15 (1.43 to 3.24$)$ & $<0.001$ & 2.14 (1.37 to 3.34$)$ & 0.001 & $1.36(0.94$ to 1.97$)$ & 0.107 & 1.40 (0.95 to 2.07$)$ & 0.092 \\
\hline Paediatric pulmonologists $\dagger$ & $0.17(0.08$ to 0.36$)$ & $<0.001$ & 0.24 (0.11 to 0.55$)$ & 0.001 & 0.34 (0.15 to 0.77$)$ & 0.010 & $0.46(0.20$ to 1.08$)$ & 0.076 \\
\hline Hospital based vs practice & $0.29(0.18$ to 0.47$)$ & $<0.001$ & 0.25 (0.15 to 0.42$)$ & $<0.001$ & $0.44(0.30$ to 0.65$)$ & $<0.001$ & $0.46(0.30$ to 0.70$)$ & $<0.001$ \\
\hline$>50$ patients vs less & $0.81(0.42$ to 1.59$)$ & 0.548 & $1.60(0.78$ to 3.30$)$ & 0.203 & 0.62 (0.36 to 1.08 ) & 0.091 & $0.86(0.47$ to 1.57$)$ & 0.632 \\
\hline \multicolumn{9}{|l|}{ Antibiotics } \\
\hline French (vs German) & $2.62(1.76$ to 3.90$)$ & $<0.001$ & 2.83 (1.84 to 4.35$)$ & $<0.001$ & 1.41 (0.95 to 2.11 ) & 0.090 & 1.41 (0.94 to 2.13 ) & 0.100 \\
\hline
\end{tabular}

Unadjusted and adjusted odds ratios were derived from ordered logistic regression.

*Adjusted for all variables in the list; †vs general paediatricians and other paediatric subspecialists; tregressions are based on 406 (2001) and 471 questionnaires (2006) for salbutamol, on 384 (2001) and 449 questionnaires (2006) for inhaled corticosteroids and on 386 (2001) and 449 questionnaires (2006) for antibiotics.

Theophylline and ribavirin were prescribed for very few patients in both surveys.

\section{Determinants of reported drug use in 2001 and 2006}

In 2001, salbutamol, ICS and antibiotics for outpatients were prescribed more often by physicians living in the French speaking part of Switzerland (table 4). The same was true for the other drugs not shown in table 4. This difference had narrowed or disappeared by 2006. In both surveys, all drugs tended to be prescribed less often by paediatric pulmonologists compared with general paediatricians, by hospital physicians compared with those working in private practice and by doctors treating more than 50 children per year compared with those treating fewer cases.

The decrease in the prescription of salbutamol for outpatients between the two surveys was seen in all subgroups: French and German speaking, hospital based and primary care physicians, paediatric pulmonologists and generalists ( $\mathrm{p}$ value (for trend) $\leqslant 0.002$ for all subgroups) (fig 1 ). The same was true for the decrease in reported use of other drugs (data not shown).

\section{DISCUSSION}

This is, to our knowledge, the first study that has demonstrated a clinically relevant change in the management of acute bronchiolitis before and after introduction of national guidelines. We found a large reduction in the reported prescription for most drugs, most prominently for bronchodilators, inhaled steroids and antibiotics, and among all paediatricians (hospital and practicing paediatricians, paediatric pulmonologists and generalists/other subspecialists). The simple but labour intensive interventions taken to implement these new guidelines, tailored to the needs of hospital based and primary care paediatricians, have proved highly effective.
Figure 1 Frequency of reported prescription of salbutamol in outpatients with acute bronchiolitis in 2001 and 2006, by groups of participating physicians. Frequency was reported as always, sometimes, high risk and never. Missing values are also indicated. FR, French speaking; GE, German speaking; Gen, general paediatricians and other subspecialists; Hosp, hospital based physicians; Pract, physicians working in primary care practices; Pulm, paediatric pulmonologists. p Values (from trend tests) for differences between the two surveys were $\leqslant 0.002$ in all subgroups.

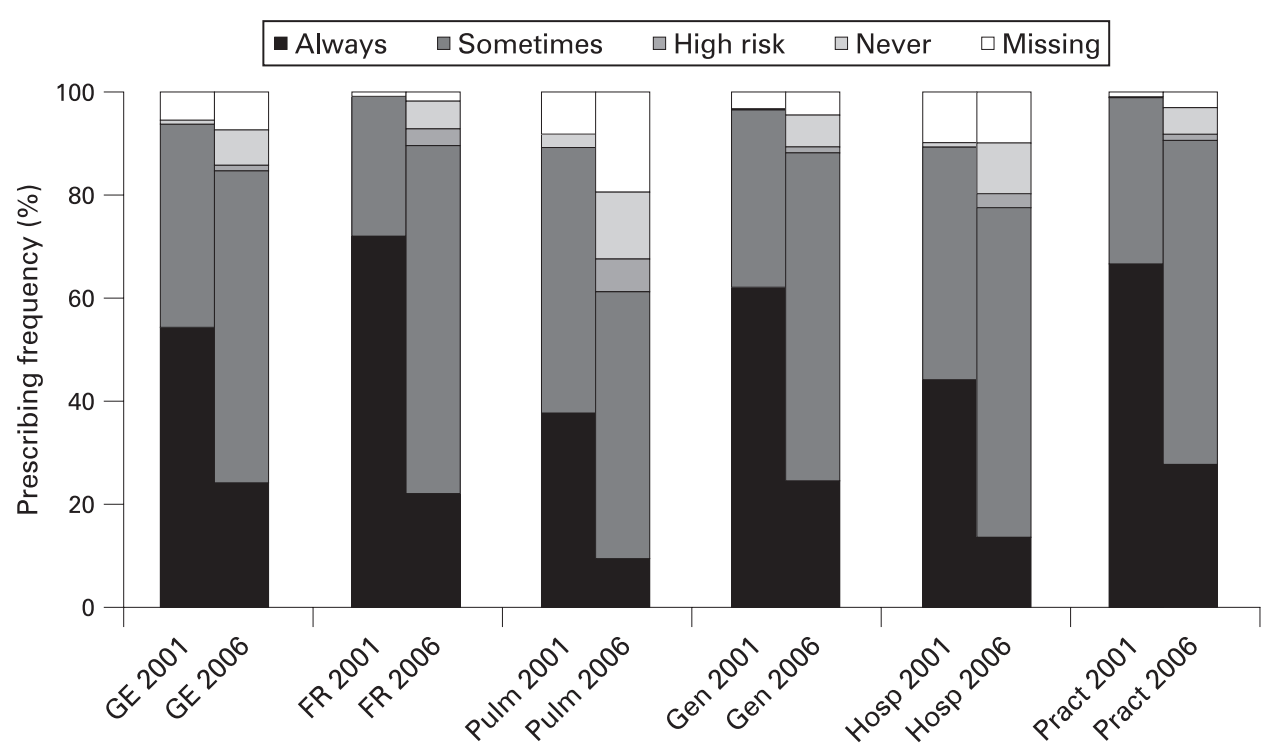




\section{Methodological considerations}

The effect of the new guidelines was assessed by nationwide surveys of all qualified paediatricians in Switzerland before and after their introduction, using the same methodology. The questionnaire, although not formally validated, had been used in previous surveys. ${ }^{21}$ The response rates of $58 \%$ and $54 \%$ are relatively good for a survey among physicians using only a single mailing. Also, the group of non-responders is likely to include colleagues not treating children with bronchiolitis at the time of the survey (eg, retired colleagues, physicians temporarily out of work and subspecialists working in other fields). It is likely that non-responders differed from responders (for instance by age, gender and awareness of new medical literature) but it seems unlikely that the characteristics of non-responders had changed substantially between the two surveys. Given the similar response rates and similar characteristics of respondents in the two surveys, we do not think that the change between the two surveys could be explained by response bias. Also, the differences were so large that only a very strong bias could have reversed our results.

Our strategy to implement the new guidelines targeted paediatricians, and only these were included in the survey. We do not know if treatment practices also changed among general practitioners. Although general practitioners treat a significant proportion of older children in Switzerland, they see only a minority of infants. We are therefore confident that these surveys reached the majority of physicians treating infants with bronchiolitis in Switzerland.

The main limitation of our study is that we assessed selfreported prescription of drugs and not the actual behaviour of physicians in daily practice. Data of actual drug sales would be helpful to support our findings. Unfortunately, in Switzerland, available data on drug sales are not broken down by age. The use of inhaled corticosteroids via nebulisers in the paediatric hospital setting has certainly decreased dramatically over the past years (personal communication of hospital based pharmacists and drug company salespersons). Therefore, although it is likely that the new guidelines have reduced costs in the treatment of bronchiolitis in infants and preschool children, which together with other wheezing disorders account for a considerable proportion of total health care costs, ${ }^{27}$ the current study is not designed to prove this assumption.
It could be argued that the time trends in drug prescription were not a response to the new Swiss guidelines but rather a consequence of the accumulating evidence on this topic in general, including other reviews and guidelines. There are three arguments against this. Firstly, the scientific evidence that no drug changes the natural course of acute bronchiolitis had been available for decades, and was reflected in the scarce use of drugs in Australian paediatricians nearly 10 years ago (table 5), perhaps because of their published guidelines in $1993 .{ }^{21}$ Because the Swiss had not implemented this evidence by 2001, it is unlikely that such a large change would have occurred without an intervention within the short period of 5 years. Secondly, at the time of our first survey, Australia was the only country with published guidelines, ${ }^{21}$ and the American Academy of Pediatrics did not publish their recommendations until October 2006, ${ }^{10}$ shortly after our second survey had taken place. Thirdly, the decrease was seen for all drugs except for nasal drops which were the only medications recommended in the new guidelines. However, we cannot definitely exclude the fact that other publications have contributed to the observed change in behaviour of Swiss paediatricians.

\section{Comparison with other studies}

There are only a few published reports on management practices of acute bronchiolitis in other countries (table 5). ${ }^{17182128}$ Compared with the survey among the European Society for Paediatric Infectious Disease ${ }^{17}$ and the Canadian retrospective study in nine tertiary hospitals, ${ }^{18}$ the Swiss paediatricians have improved their management towards a more evidence based treatment. However, they still prescribe more drugs than their colleagues in Australia. ${ }^{21}$ The Irish study ${ }^{29}$ presenting a clinical scenario of a 3-month-old infant with severe respiratory syncytial virus infection is not directly comparable.

The findings that hospital physicians prescribed less drugs than practitioners and paediatric pulmonologists less than general paediatricians is not surprising. In a study on determinants of health costs and patterns of care in patients with asthma in Switzerland, ${ }^{30}$ Szucs and colleagues found that total direct costs were higher among general practitioners compared with specialists. They also showed that French

Table 5 International comparison of inpatient management for infants with acute bronchiolitis

\begin{tabular}{|c|c|c|c|c|c|c|}
\hline & \multirow{2}{*}{$\begin{array}{l}\text { Canada } \\
1994^{*}\end{array}$} & \multirow{2}{*}{$\begin{array}{l}\text { Europe } \\
1995 \dagger\end{array}$} & \multirow{2}{*}{$\begin{array}{l}\text { Australia } \\
1998 *\end{array}$} & \multicolumn{2}{|c|}{ Switzerland } & \multirow{2}{*}{$\begin{array}{l}\text { Belgium } \\
20039\end{array}$} \\
\hline & & & & $2001 \S$ & $2006 \S$ & \\
\hline \multicolumn{7}{|l|}{ Salbutamol (\%) } \\
\hline All patients & 85 & 61 & 7 & 55 & 18 & NA \\
\hline Sometimes & NA & NA & 69 & 42 & 72 & NA \\
\hline Only high risk patients & NA & 34 & 12 & 1 & 3 & NA \\
\hline Never & NA & 5 & 9 & 2 & 7 & 11 \\
\hline \multicolumn{7}{|l|}{ Steroids $(\%)$} \\
\hline All patients & 28 & 11 & 1 & 27 & 7 & 2 \\
\hline Sometimes & NA & NA & 35 & 52 & 45 & 32 \\
\hline Only high risk patients & NA & 69 & 22 & 6 & 8 & 20 \\
\hline Never & NA & 19 & 38 & 15 & 40 & 46 \\
\hline \multicolumn{7}{|l|}{ Ribavirin (\%) } \\
\hline All patients & 6 & 0 & 0 & 0 & 0 & NA \\
\hline Sometimes & NA & NA & 1 & 2 & 1 & NA \\
\hline Only high risk patients & NA & 57 & 11 & 6 & 8 & NA \\
\hline Never & NA & 43 & 83 & 90 & 91 & NA \\
\hline
\end{tabular}

${ }^{*}$ Retrospective study in hospitals. ${ }^{18}+$ Questionnaire survey with specialised paediatric infectious disease physicians. ${ }^{17}$

\$Questionnaire survey with paediatricians-response rate $62 \%{ }^{21} \S$ Current study. Questionnaire survey with paediatriciansresponse rate $40 \%$. NA, not available. ${ }^{28}$ 
speaking physicians prescribed more drugs than doctors in the German speaking part of the country, resulting in a higher economic burden. This is true for other disorders and is reflected by higher premiums for medical insurance in the French speaking part of Switzerland. In addition, the French speaking part of Switzerland is strongly influenced by French language scientific literature. For instance, publications on chest physiotherapy in children with bronchiolitis from a Belgian kinesiologist, published in French, ${ }^{31}$ seem to have had a large impact on French speaking paediatricians in Switzerland (personal communication with French speaking colleagues). It is important to note that this gap between the French and German speaking part of Switzerland narrowed or disappeared after implementation of the new guidelines (fig 1).

Even though drug use decreased enormously between the two surveys, we need to say that a large number of Swiss paediatricians continued to use supplementary drugs for both outpatients and inpatients. More than $90 \%$ of the paediatricians still indicated that they used bronchodilators, but mainly for the purpose of a treatment trial ("sometimes" users) because of the clinical difficulties of differentiating acute bronchiolitis from viral induced obstructive bronchitis (wheezing) and the first episode of asthma in older infants, respectively. ${ }^{32}$

\section{How to implement change in clinical practice?}

Difficulties in implementing evidence based medicine into clinical practice are well recognised. ${ }^{168}$ The barriers to the adoption of research findings in clinical practice are complex and many theories and a multitude of factors that may affect a successful implementation of evidence have been described..$^{5} 72133$ Relying on the passive diffusion of information is doomed to failure in a global environment with about 10000 new randomised trials published annually. ${ }^{1}$ A common approach is to summarise research findings in guidelines and consensus views in medical journals. Evidence based guidelines can contribute to improved care only if they succeed in changing actual practice. ${ }^{3}$ However, many physicians are unaware of the guidelines or, at least, not influenced by them because improving knowledge does not necessarily alter behaviour. ${ }^{64}$ In particular, one has to bear in mind that health professionals have their own experiences, beliefs and perceptions about appropriate practice; attempts to change practice which ignore these factors are unlikely to succeed. Circulation of guidelines without a tailored implementation strategy may have little impact on the behaviour of health professionals. ${ }^{69}$

A systematic review of 235 studies of guideline dissemination and implementation strategies found a small to moderate improvement in care, with an average of $10 \%$ improvement across the studies. ${ }^{4}$ Most of these studies investigated change in clinical practice in the hospital setting, not daily behaviour of practitioners. For example, in a hospital setting in Cincinnati (USA), an evidence based clinical practice guideline for managing bronchiolitis was highly successful in its first year of implementation, with significant reductions in the use of all respiratory therapies. ${ }^{35}$ The use of $\beta_{2}$ agonists decreased by $30 \%$, and the mean cost for respiratory care services by $77 \%$. Subsequently, Kotagal and colleagues introduced the same guidelines in seven hospitals but with varying success. ${ }^{36}$

To achieve a change in clinical practice we believe that the following points need to be considered. Firstly, there must be a few individuals who are motivated to facilitate the change. Secondly, national or local guidelines, reflecting the needs of the local population, should be developed from existing international guidelines and the current available literature by a process of consultation with all of the relevant medical staff. This process will encourage a sense of "ownership" of the local guidelines. Thirdly, having developed local guidelines, implementation must include interactive educational sessions with all relevant practitioners. Finally, implementation activities should be evaluated to examine their effectiveness and the results disseminated to all relevant practitioners. ${ }^{21}$

\section{Why was the present strategy successful?}

We therefore believe that the following components of our strategy were crucial to its success. (1) The guidelines were developed in a working group which included representatives from all regions and all languages in Switzerland, hospital physicians as well as respiratory physicians working in private practice. Therefore, a broad consensus was reached. (2) The new guidelines were broadly presented by a number of dedicated paediatric respiratory physicians in various national and local meetings, at university hospitals and regional hospitals in advanced training programmes for registrars and continuing education for practitioners, and in all relevant medical publications, not only in scientific ones, but also in popular medical tabloids. (3) The implementation package included an information leaflet for distribution to parents which was supported by the Swiss Society of Paediatrics. Under the pressure of demanding or overanxious parents and overcrowded medical practices it is easier for a clinician to prescribe a drug instead of trying to explain to parents that no medication will help. This fact is well known by paediatricians who are confronted daily with viral and other self-limiting diseases such as coughs or painful middle ear infections. This parental pressure might perhaps explain the increased use of nose drops, which we found in parallel to the decreased use of other medications. The information leaflet might also have helped to signal to parents that there is a national consensus for treatment of this condition and there is no evidence to support the use of drugs in the management of bronchiolitis. In addition, Switzerland is a small country with only 7 million inhabitants with a very active and collaborative group of paediatric pulmonologists who have built up a good care and information network.

In summary, we showed that the creation and tailored implementation of new bronchiolitis guidelines in Switzerland was followed by a clinically significant change in the management of acute bronchiolitis in all paediatricians. The relatively simple but labour intensive measures taken to implement the new guidelines, tailored to the respective needs of hospital based and primary care based paediatricians, specialists and generalists, have thus proven to be highly effective.

Acknowledgements: We thank all Swiss paediatricians who participated in our study, and Ben Spycher and Marie-Pierre Strippoli for comments on earlier versions of this manuscript.

Funding: CEK was supported by the Swiss National Science Foundation (PROSPER grant No 3233-069348 and 3200-069349). The mailing of the first survey was supported by an unrestricted grant of CHF 2000 from AstraZeneca. The second survey was sponsored by the Children's Hospital St Gallen.

Competing interests: None.

\section{REFERENCES}

1. Grol R, Grimshaw J. From best evidence to best practice: effective implementation of change in patients' care. Lancet 2003;362:1225-30.

2. Godlee F. Getting evidence into practice. Needs the right resources and the right organisation. BMJ 1998;317:6.

3. Higgins BG. The modern way of developing clinical guidelines. Thorax 2007;62:1022-4.

4. Grimshaw JM, Eccles MP. Is evidence-based implementation of evidence-based care possible? Med J Aust 2004;180:S50-1. 
5. Haynes B, Haines A. Barriers and bridges to evidence based clinical practice. BMJ 1998;317:273-6.

6. Powell CV. How to implement change in clinical practice. Paediatr Respir Rev 2003:4:340-6.

7. Grol R, Wensing M. What drives change? Barriers to and incentives for achieving evidence-based practice. Med J Aust 2007;180:S57-60.

8. Bero LA, Grilli R, Grimshaw JM, et al. Closing the gap between research and practice: an overview of systematic reviews of interventions to promote the implementation of research findings. The Cochrane Effective Practice and Organization of Care Review Group. BMJ 1998;317:465-8.

9. Shaw B, Cheater F, Baker R, et al. Tailored interventions to overcome identified barriers to change: effects on professional practice and health care outcomes. Cochrane Database Syst Rev 2005;3:CD005470.

10. American Academy of Pediatrics. Diagnosis and management of bronchiolitis. Pediatrics 2006:118:1774-93.

11. Gadomski AM, Bhasale AL. Bronchodilators for bronchiolitis. Cochrane Database Syst Rev 2006; 3:CD001266.

12. Hartling L, Wiebe N, Russell K, et al. Epinephrine for bronchiolitis. Cochrane Database Syst Rev 2004;1:CD003123.

13. Patel H, Platt R, Lozano JM, et al. Glucocorticoids for acute viral bronchiolitis in infants and young children. Cochrane Database Syst Rev 2004;3:CD004878.

14. Perrotta C, Ortiz Z, Roque M. Chest physiotherapy for acute bronchiolitis in paediatric patients between 0 and 24 months old. Cochrane Database Syst Rev 2006;4:CD004873.

15. Spurling GK, Fonseka K, Doust J, et al. Antibiotics for bronchiolitis in children. Cochrane Database Syst Rev 2007;1:CD005189.

16. Ventre K, Randolph AG. Ribavirin for respiratory syncytial virus infection of the lower respiratory tract in infants and young children. Cochrane Database Syst Rev 2006; 4:CD000181.

17. Kimpen JL, Schaad UB. Treatment of respiratory syncytial virus bronchiolitis: 1995 poll of members of the European Society for Paediatric Infectious Diseases. Pediatr Infect Dis J 1997; 16:479-81.

18. Wang EE, Law BJ, Boucher FD, et al. Pediatric Investigators Collaborative Network on Infections in Canada (PICNIC) study of admission and management variation in patients hospitalized with respiratory syncytial viral lower respiratory tract infection. J Pediatr 1996;129:390-5.

19. Barben J, Hammer J. Current management of acute bronchiolitis in Switzerland. Swiss Med Wkly 2003:133:9-15.

20. Kuehni C. Phenotype specific treatment of obstructive airways disease in infancy and childhood: New recommendations of the Swiss Paediatric Pulmonology Group. Swiss Med Wkly 2005:135:95-100.
21. Barben JU, Robertson CF, Robinson PJ. Implementation of evidence-based management of acute bronchiolitis. J Paediatr Child Health 2000;36:491-7.

22. Barben J, Hammer J. Behandlung der Bronchiolitis im Säuglingsalter. Empfehlungen der Schweizerischen Arbeitsgemeinschaft für Pädiatrische Pneumologie (SAPP). Paediatrica 2003;14:18-21.

23. Schweizerische Arbeitsgemeinschaft für Pädiatrische Pneumologie. Empfehlungen zur Behandlung von obstruktiven Atemwegserkrankungen im Säuglings- und Kindesalter. Asthma bronchiale und rezidivierende obstruktive Bronchitiden. Paediatrica 2004;15:13-28.

24. Barben J, Hammer J. Akute Bronchiolitis. Pädiatr Prax 2003;63:611-20.

25. Barben J, Hammer J. Behandlung der akuten Bronchiolitis im Säuglingsalter. Schweiz Med Forum 2004;4:251-3.

26. Barben J, Hammer J. Zur Kunst etwas zu verkaufen, das nicht benötigt wird Paediatrica 2005;16:3

27. Stevens CA, Turner D, Kuehni CE, et al. The economic impact of preschool asthma and wheeze. Eur Respir J 2003;21:1000-6.

28. de Bilderling G, Bodart E. Bronchiolitis management by the Belgian paediatrician: discrepancies between evidence-based medicine and practice. Acta Clin Belg 2003:58:98-105

29. Cahill $\mathbf{P}$, Finan E, Loftus BG. Management of bronchiolitis: current practices in Ireland. Ir Med J 2002:95:167-9.

30. Szucs TD, Anderhub HP, Rutishauser M. Determinants of health care costs and patterns of care of asthmatic patients in Switzerland. Schweiz Med Wochenschr 2000;130:305-13.

31. Postiaux G, Dubois R, Marchand E, et al. Effets de la kinésithérapie respiratoire associant expiration lente prolongée et toux provoquée dans la bronchiolite du nourrisson. Kinesither Rev 2006;55:35-41.

32. Kellner JD, Ohlsson A, Gadomski AM, et al. Efficacy of bronchodilator therapy in bronchiolitis. A meta-analysis. Arch Pediatr Adolesc Med 1996;150:1166-72.

33. Pathman DE, Konrad TR, Freed GL, et al. The awareness-to-adherence model of the steps to clinical guideline compliance. The case of pediatric vaccine recommendations. Med Care 1996;34:873-89.

34. Lomas J, Anderson GM, Domnick-Pierre K, et al. Do practice guidelines guide practice? The effect of a consensus statement on the practice of physicians. N Engl J Med 1989;321:1306-11.

35. Perlstein PH, Kotagal UR, Bolling C, et al. Evaluation of an evidence-based guideline for bronchiolitis. Pediatrics 1999;104:1334-41.

36. Kotagal UR, Robbins JM, Kini NM, et al. Impact of a bronchiolitis guideline: a multisite demonstration project. Chest 2002;121:1789-97.

\section{Let us assist you in teaching the next generation}

Figures from all articles on our website can be downloaded as a PowerPoint slide. This feature is ideal for teaching and saves you valuable time. Just click on the image you need and choose the "PowerPoint Slide for Teaching" option. Save the slide to your hard drive and it is ready to go. This innovative function is an important aid to any clinician, and is completely free to subscribers. (Usual copyright conditions apply.) 